Portland State University

PDXScholar

$7-1-2020$

\title{
Using Spoken Dialogue Technology for L2 Speaking Practice: What Do Teachers Think?
}

\author{
Veronika Timpe-Laughlin \\ Educational Testing Service \\ Tetyana Sydorenko \\ Portland State University, tsydorenko@pdx.edu \\ Phoebe Daurio \\ Portland State University, phoebed@pdx.edu
}

Follow this and additional works at: https://pdxscholar.library.pdx.edu/ling_fac

Part of the Applied Linguistics Commons

Let us know how access to this document benefits you.

\section{Citation Details}

Published as: Timpe-Laughlin, V., Sydorenko, T., \& Daurio, P. (2020). Using spoken dialogue technology for L2 speaking practice: what do teachers think? Computer Assisted Language Learning, 1-24.

This Post-Print is brought to you for free and open access. It has been accepted for inclusion in Applied Linguistics Faculty Publications and Presentations by an authorized administrator of PDXScholar. Please contact us if we can make this document more accessible: pdxscholar@pdx.edu. 


\title{
Using spoken dialogue technology for L2 speaking practice: What do teachers think?
}

\author{
V. TIMPE-LAUGHLIN ET AL. \\ Computer Assisted Language Learning
}

\section{Veronika Timpe-Laughlin ${ }^{\mathrm{a}}$; Tetyana Sydorenko ${ }^{\mathrm{b}}$; Phoebe Daurio ${ }^{\mathrm{c}}$}

aEducational Testing Service, Princeton, NJ, USA;

bepartment of Applied Linguistics, Portland State University, Portland, OR, USA;

'Intensive English Language Program, Portland State University, Portland, OR, USA

Supplemental data for this article is available online at https://doi.org/10.1080/09588221.2020.1774904.

\section{CONTACT Veronika Timpe-Laughlinvlaughlin@ets.org}

\begin{abstract}
Often, second/foreign (L2) language learners receive little opportunity to interact orally in the target language. Interactive, conversation-based spoken dialog systems (SDSs) that use automated speech recognition and natural language processing have the potential to address this need by engaging learners in meaningful, goal-oriented speaking practice. However, these technology-based learning tools are often developed without input from teaching professionals. As part of a larger development effort, this study examined English as a second language (ESL) teachers' perceptions regarding SDS-based speaking tasks, addressing the following research questions: (a) What do teachers think about the SDS-based tasks? (b) How would they use them in the context of their English instruction? Overall, 16 ESL instructors in an intensive English program in the United States were asked to interact with four SDS-based speaking tasks designed to elicit specific linguistic phenomena (e.g. making requests; wh-questions). The teachers completed a survey after each task to gauge their user experience, level of engagement, and perceptions of the usefulness of the tasks for their teaching contexts. A subgroup of instructors $(n=7)$ also participated in audiorecorded focus group meetings. Descriptive statistics were calculated for each survey item and the open-ended responses from the surveys and focus groups were analyzed qualitatively for major themes. The findings show that teachers had positive views of the SDS tasks' potential for speaking practice and diagnostic purposes, primarily in a flipped classroom model. Their perceptions seemed to be related to their own user experience and, in particular, to the perceived authenticity of a given task.
\end{abstract}

Keywords: English; speaking; spoken dialogue technology; tasks; teacher perceptions

\section{Introduction}

Speaking skills are a key component of the curriculum in second and foreign language (L2) teaching in order to enable learners to use the target language when interacting with others. However, for language learners - especially those who learn the additional language as a foreign language - it can be challenging to find opportunities to practice their 
speaking and interaction abilities in the target language. The classroom tends to provide only a limited amount of time for individual speaking practice and it can be difficult to find an interlocutor outside of class.

Recent developments in speech recognition and spoken dialogue system (SDS) technology have led to the creation of interactive, conversation-based systems that can provide a potential solution. For example, fully automated, multiturn spoken dialogues enable learners to practice speaking in a target language anytime, anywhere, even when an instructor is not available (Cucchiarini \& Strik, 2019). Interacting with these dialogs on a computer as opposed to a human interlocutor, and using the computer in a location of choice, may create less anxiety and more willingness to engage in oral interaction in the target language (see Golonka, Bowles, Frank, Richardson, \& Freynik,2014, for a review). Recent improvements in automatic speech recognition and SDS infrastructure have led to the development of conversation-based systems that also can provide targeted feedback, thus giving learners actionable information about how to improve their speaking proficiency in a target language. Hence, interactive SDS-based activities may provide a low-stakes environment for L2 learners to practice their oral skills.

The majority of research to date has examined the performance of spoken dialogue systems with regard to learners' accented speech and their attitudes toward such technology (e.g. Evanini et al.,2018; Morton, Gunson, \& Jack, 2012). However, to our knowledge, only two studies have examined teachers' reactions to SDS tasks (Chen,2011; van Doremalen, Boves, Colpaert, Cucchiarini, \& Strik, 2016). Like 'the lynchpin' around which learning events occur (Guichon \& Hauck, 2011, p. 188), instructors determine if and how technology is implemented (Arnold \& Ducate, 2015). For this reason, Mishan and Timmis (2015) stressed the importance of involving instructors early on in the material or task design process. Hence, in this study we explored teachers' perceptions of SDS tasks and sought their insights into how teachers would implement such speaking tasks in their L2 instruction in order to consider how the tasks may be refined for this purpose.

\section{Literature review}

\section{SDS tasks for language learning}

In recent years, SDS technology has begun to play a prominent role in computer-assisted language learning (CALL) applications (e.g. Bernstein, Najmi, \& Ehsani, 1999; Bibauw, François, \& Desmet, 2015; 2019; Ellis \& Bogart, 2007; Eskenazi, 2009; Godwin-Jones, 2009; Golonka et al., 2014; Lee, Noh, Lee, Lee, \& Lee,2012). SDS-based conversation tasks, in particular, offer a variety of benefits. First, they provide opportunities for the multi-turn goaloriented practice of extended discourse. Such practice aligns both with the interaction approach to second language acquisition (SLA) (e.g. Pica, 2013; Plonsky \& Gass, 2011) and task-based language teaching (e.g. Long, 2015). Second, they provide a safe environment because many learners perceive interaction with a computer system to be less risky or face-threatening than an interaction with a person (Ayedoun, Hayashi, \& Seta, 2015; see Golonka et al., 2014, for a review). Additionally, learners can engage in the repeated practice of the same SDS-based task, which, according to Skill Acquisition Theory, can increase fluency and automatized production (e.g. DeKeyser, 2007, 2010).

In a recent overview of dialogue-based CALL, Bibauw et al.(2019) provided a useful categorization framework. In their view, tasks that involve dialogic learner/computer interactions can be divided into four strands: '(1) "intelligent CALL" (ICALL), (2) computer-assisted pronunciation training (CAPT), (3) spoken dialogue systems and conversational agents (SDS/CA), and (4) chatbots' (p. 8). The focus of ICALL is to provide feedback on learner errors. CAPT delivers pronunciation training, which includes feedback on accuracy. SDSs, which are the focus of our paper, engage learners in goal-oriented conversations, whereas chatbots center around open-ended nongoal-oriented conversations. Some examples of multimodal spoken dialogue systems that have been used for L2 learning include SPELL (Anderson, Davidson, Morton, \& Jack, 2008), DEAL (Hjalmarsson, Wik, \& Brusk, 2007), Tactical 
Language and Culture Training Systems (TLCTS) (Johnson \& Valente,2009), and HALEF, the open-source standard-compliant telephony-based modular spoken dialog system used in the context of this study (for a detailed description of the system see Ramanarayanan et al.,2017; Suendermann-Oeft, Ramanarayanan, Teckenbrock, Neutatz, \& Schmidt, 2015).

Given that current systems are not error-free in recognizing and reacting to speech, the majority of research on SDSs has examined speech recognition error rates with regard to learners' accented speech and attitudes toward such systems. General findings reveal that while automatic speech recognition (ASR) error rates are still relatively high (e.g. Evanini et al., 2018; Morton et al., 2012), language learners tend to find various tasks engaging, enjoyable, and motivating (e.g. Evanini et al., 2018; Morton et al., 2012; Timpe-Laughlin et al., 2017). Learners have also reported increased confidence to communicate (Anderson et al.,2008; Ayedoun et al., 2015; Surface, Dierdorff, \& Watson, 2007). Overall, the results reported by studies conducted with L2 learners and SDS-based tasks suggest that SDSs may be useful for improving speaking proficiency (see also Bibauw et al.'s 2019 synthesis).

\section{The role of teachers in designing and using learning materials}

Since materials should be designed with a given learner or group of learners in mind (Saraceni, 2003; Tomlinson, 2003), it is valuable to involve teachers in material design or adaptation processes, as they are familiar with their learners' linguistic strengths and weaknesses (Madsen \& Bowen, 1978; Tomlinson \& Masuhara, 2004). Mishan and Timmis (2015) stressed the importance of a principled and ongoing evaluation of English teaching materials that starts at the onset of the design process. Within the three common stages of preuse, whilst use, and postuse evaluation (Tomlinson, 2003), teacher opinions are essential, especially at the preuse stage as teachers may evaluate materials based on (a) how likely they are to motivate the learners, (b) level of authenticity, (c) clarity of organization, and (d) practicality (availability, durability, price) (e.g. McGrath, 2002; Mishan \& Timmis, 2015). Hence, teachers are wellpositioned to provide initial input that can further influence the iterative design process.

Some researchers have examined teachers' use or beliefs about the use of specific types of technologies, including learning management systems (e.g. Beatty \& Ulasewicz,2006), mobile technology (van Praag \& Sanchez, 2015), clickers (e.g. Roush \& Song, 2013), blogs (e.g. Dippold, 2009), digital flashcards (e.g. Alnajjar \& Brick, 2019), synchronous voice-based, computer-mediated communication (e.g. Bueno Alastuey, 2011), corpus tools (Bunting, 2013), and others. However, such studies are limited, as evidenced by a comprehensive review conducted by Egbert, Huff, McNeil, Preuss, and Sellen (2009). Egbert et al. concluded that while student voices are relatively more researched, teacher voices should be more present in the design and use of various CALL applications - a call we aim to respond to in this study.

Despite the importance of involving teachers in the design and development process for CALL-related materials, the body of research that systematically investigates teachers' perceptions of SDS-based conversation tasks is particularly limited. van Doremalen et al. (2016) and Chen (2011) constitute two examples of research into teachers' perceptions of SDS-based tasks. Both of these studies focus on technological feasibility and the system's usability and general effectiveness. In van Doremalen et al. (2016), after familiarizing themselves with the system, teachers were asked to comment on the usability of the system, specifically for out-of-class use. Participants answered Likert-scale questions on performance expectancy (e.g. whether learners would be able to learn Dutch pronunciation, morphology, and syntax better with the system than without it), effort expectancy (e.g. whether the program is easy to use for teachers and students), technological means for using the program (e.g. access to the microphone and Internet), social influence (what coworkers would think of teachers using this program), and whether teachers would ultimately use the program with their students. A subset of teachers was asked to elaborate further on their answers during an interview. In these interviews, teachers provided additional insights into what was important to them in terms of the 
system's usability: user control of the system; flexibility and efficiency of use; and system's performance in terms of ASR error rates, clarity of help and documentation, and other similar themes. In Chen (2011), a more open-ended, methodological approach was taken: preservice teachers were asked to write an evaluation report on the strengths and weaknesses of the system after using it for two hours. Some strengths mentioned by teachers were a low-anxiety speaking environment, self-access learning, grouping of exercises by difficulty level, the possibility to practice both pronunciation and less discrete tasks, and the tracking and logging function. Some weaknesses were limited corrective feedback, high ASR error rates, synthesized rather than human voices, lack of emphasis on stress and intonation, and technical problems. While providing useful insights for further system design, the studies did not examine in detail how teachers would utilize such tasks in their instruction.

To summarize, it is a teacher's responsibility to make 'learning more meaningful, motivating, and rooted in the personal interests of students' (Warschauer \& Cook, 1999, p. 32). Thus, in addition to examining teachers' beliefs about technology implementation in general, it is particularly valuable to understand the specific choices that an instructor makes regarding the use of learning tools within a given educational context (Chao, 2015; Warschauer, 1998, 1999). These beliefs will determine which CALL applications are used in the classroom and, more specifically, how they are implemented (Arnold \& Ducate, 2015; Hubbard, 2008). Most SDS systems developed for learningoriented uses are stillat a prototype stage (see Bibauw etal.,2019), though some are now becoming more viablefor implementation (e.g. HALEF). Therefore, it might be an appropriate time to involve instructors and explore in a systematic way how L2 teachers would use SDS-based conversation tasks in their instruction.

\section{Research questions}

Given that our SDS-based conversation tasks are still being developed, gathering teachers' perceptions about them is an important step in empirically substantiating the development and vetting the potential use of these speaking activities for English language instruction. To that end, our study was guided by the following research questions:

RQ1: What do teachers think about the SDS-based tasks?

RQ2: How would they use them in the context of their English instruction?

\section{Methodology}

\section{Participants}

A total of 16 female English as a second language (ESL) teachers, ranging from 31 to 60 years of age ( $M=43.93 ; S D$ = 7.31), participated in the study. All participating instructors teach in an intensive English program at a U.S. university. Except for one teacher, all participants reported being L1 speakers of English. All participants had at least five years of teaching experience, while the majority $(n=11)$ of them reported more than 15 years of experience teaching ESL. All participants had experience teaching a variety of levels (beginning through advanced) and courses (i.e. variety of skills, including oral communication classes).

\section{Spoken dialogue system (SDS) tasks}

A total of four interactive SDS-based tasks, designed for intermediate-level ESL/English as a foreign language (EFL) learners (described below), were used in this study. When learners first view a task, they read the context and communicative objective of the task. Then, they press the 'call button' to place an audio call via a web browser to access the application. This initiates the SDS system, and a virtual speaker starts the conversation. While engaging with the system, users see the scenario information and objective as well as an image of the virtual interlocutor or other necessary information, such as an image of a menu. Learners use their conversational turn to advance their 
objective, and, using ASR, the computer responds to what the learner says. Streaming audio is processed in real time on a server that uses voice activity detection so the system can gauge the end of a user's utterance or response (Evanini et al., 2018). Overall, four different tasks were used in this study: (1) Guessing game, (2) Ordering at a coffee shop, (3) Making a request to a boss, and (4) Disputing a billingerror. Note thatFigures 1-4 show the screens as they were displayed to participants during the oral interaction with the SDS speaking activities.

\section{Figure 1. Task 1: The Guessing Game.}

\section{Guessing game}

Let's play a game. I'm one of these people. Can you guess who I am? Look at the pictures and ask yes/no questions to find out which person I am.
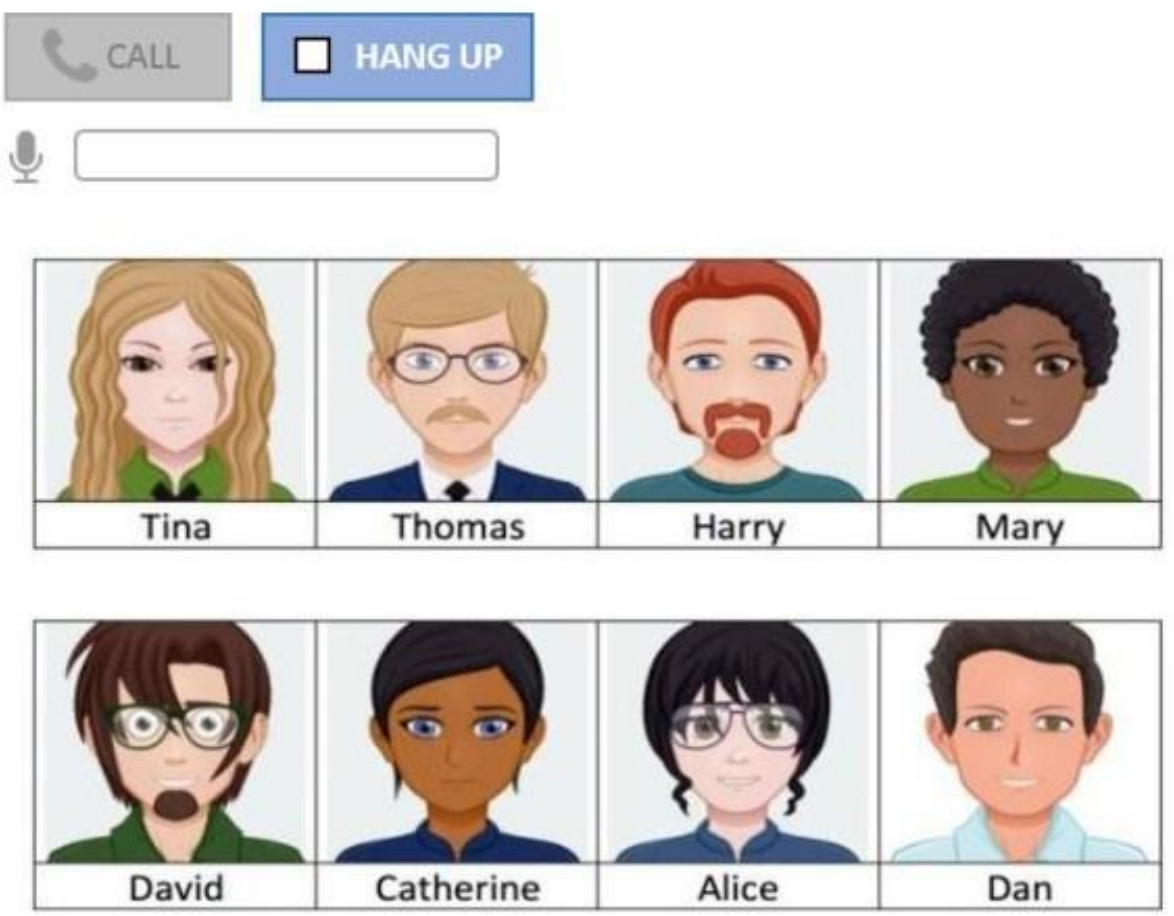

Copyright (C) Educational Testing Service. 
Figure 2. Task 2: Ordering at a coffee shop.

Your task: Get a beverage and a food item for your friend

You agreed to bring your friend John a snack and something to drink. You are now at the coffee shop.

Order one drink and one food item.

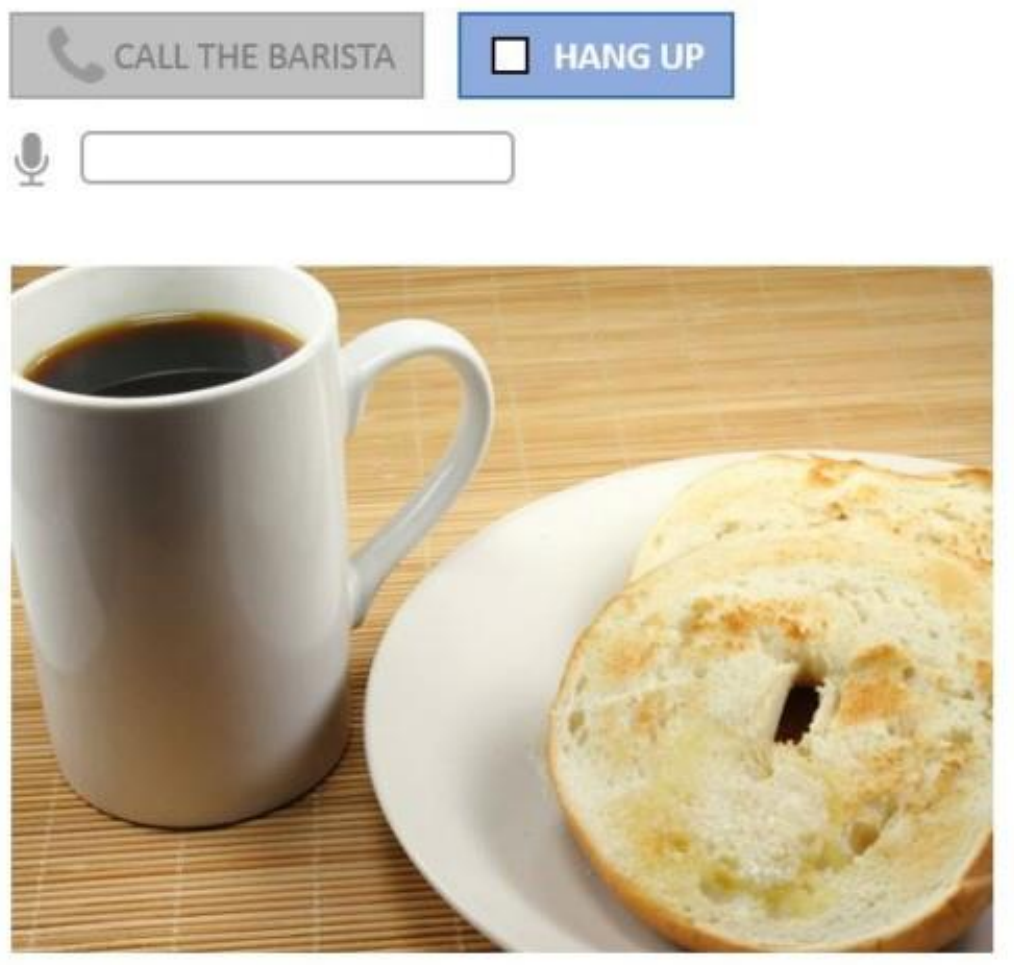

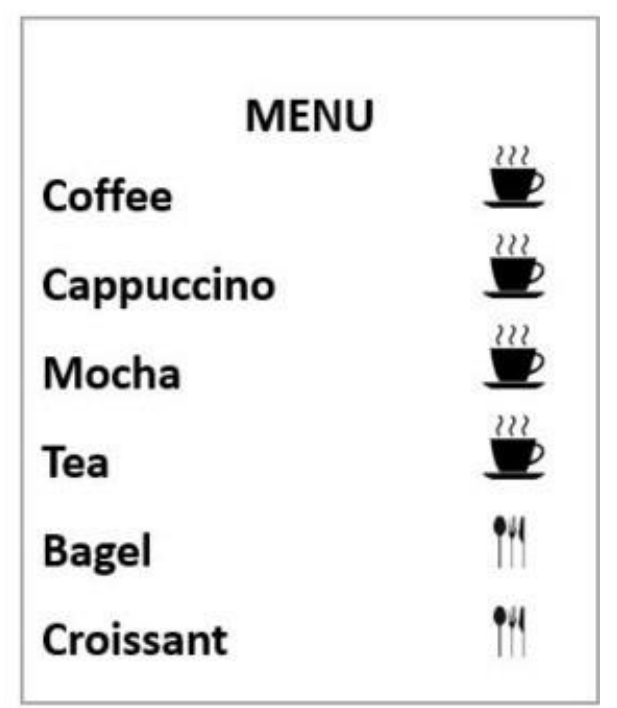

Copyright $($ C Educational Testing Service. 
Figure 3. Task 3: Making requests.

You are about to call your boss, Lisa Green. Your goals are to:

1. Get her to agree to have a meeting with you and

2. Ask her to review your presentation slides before the meeting.

Your schedule is free for the rest of the week, so any time proposed by Lisa will work for you.
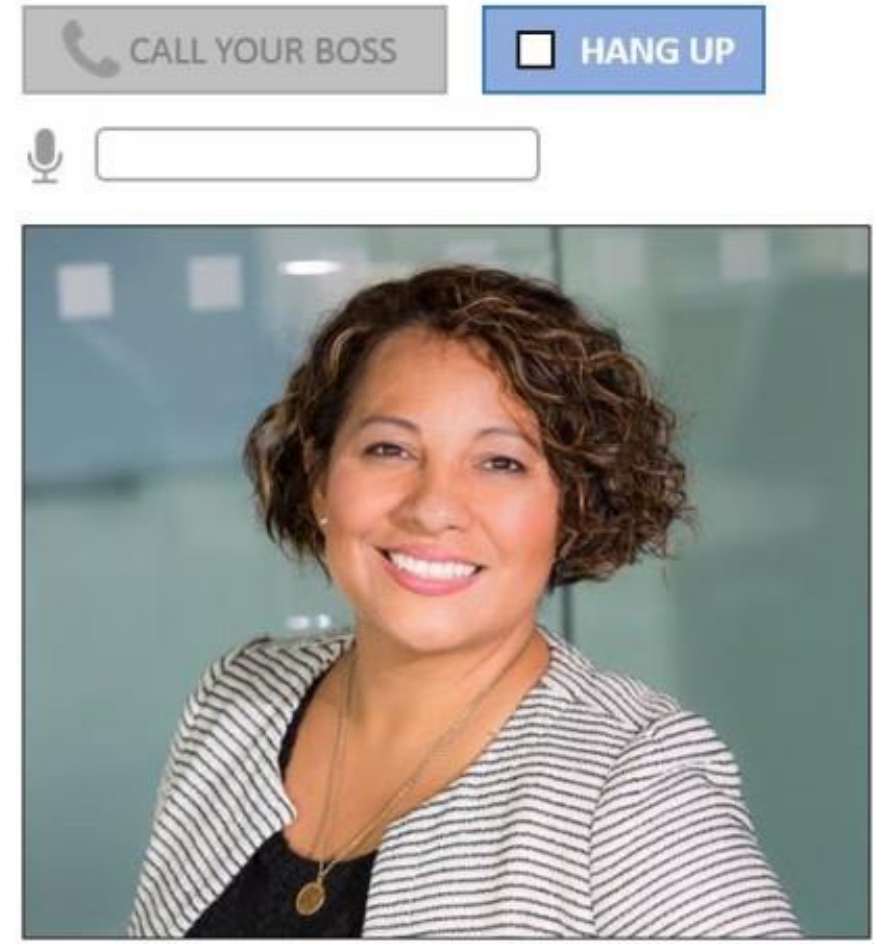

Copyright (C) Educational Testing Service. 
Figure 4. Task 4: Disputing a billing error.

\title{
Your task: Review your phone bill and then call the phone company
}

\author{
It looks like you've been charged for some international calls. You should not have these \\ charges because last month you purchased an international calling plan (for $\$ 30$ a month), \\ Which includes free unlimited international calls.
}

CALL THE PHONE COMPANY

\section{HANG UP}

Monthly Statement

Account number: $347-563-2980$

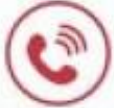

Phone number: 609-555-0191

\begin{tabular}{|ll|}
\hline Monthly service & $\$ 85.49$ \\
\hline \hline International calls & $\$ 69.80$ \\
\hline \hline Taxes (10\%) & $\$ 15.53$ \\
\hline & \\
Total & $\$ 170.82$ \\
\hline
\end{tabular}

Copyright (C) Educational Testing Service.

\section{Guessing game}

This speaking task requires users to produce yes/no questions. The user sees an image of eight characters on the screen (Figure 1) and hears the following prompt to start the conversation: 'Let's play a game. I am one of these people. Can you guess who Iam? Look at the pictures and ask yes/no questions to find out which person I am. For example, you can ask "Do you have red hair?" or "Are you wearing a green t-shirt?" Okay let's get started'. The system randomly preselects a character at the beginning of the conversation. As the user engages with the task, the system processes each yes/no question and provides feedback in the form of an affirmative or negative answer. The system also provides feedback on question formation with regard to, for example, if the yes/no question was formed grammatically incorrect. The interaction continues until the user guesses the correct character (for more details about this activity, see Evanini et al., 2018; Timpe-Laughlin et al., 2017).

\section{Ordering at a coffee shop}

In this speaking activity, learners interact with a barista at a coffee shop. Their task is to order one food item and one drink item from the menu displayed on the screen (Figure 2). This speaking activity requires learners to listen and respond to short questions that are typical in a heavily routinized interaction of ordering at a coffee shop.

\section{Making a request to a boss}

In this task, users are asked to make a call to a fictional boss named Lisa Green. As noted in the instructions (Figure 
3), this speaking task aims to elicit two different requests. First, learners need to schedule a meeting with Lisa Green and then ask her to review presentation slides before the meeting (see Timpe-Laughlin \& Evanini, in press; TimpeLaughlin et al., 2017, for more detailed information about this task).

\section{Disputing a billing error}

In this speaking task, users are asked to make a call to their phone service provider and dispute an error on their monthly bill (Figure 4). They were charged for international calls although they had purchased an international plan for $\$ 30$ last month. The goal of this task is to speak with an agent and have the incorrect charges removed from the bill.

\section{Procedure}

First, all participants $(N=16)$ were asked to respond to an online survey to obtain demographic information as well as insights into their teaching experience. Then, teachers engaged with each of the four SDS tasks. After each task, teachers completed a survey aimed at collecting their perceptions of (a) their general experiences during task engagement, (b) their opinions about each task, (c) suggestions for improving the tasks, and (d) potential implementations and uses in ESL instruction.

In addition to interacting with the tasks and responding to the online surveys, a subgroup of the participants $(n=7)$ agreed to participate in focus group interviews. The interviews were intended to expand on the information obtained in the surveys and, in particular, elicit detailed information about teachers' suggestions for potential implementation of SDS-based tasks in ESL instruction (see Appendix I for the focus group protocol). Within one week of completing the tasks, two focus group interviews were conducted with three instructors in each group. Due to time conflicts, one instructor was interviewed individually. All focus group sessions and the individual interview were audio-recorded.

\section{Analyses}

In order to explore perceived usability and to obtain recommendations for potential improvements and applications in ESL teaching, the survey and focus group/interview data were subjected to quantitative and qualitative analyses. With regard to answers to the posttask surveys, we tallied frequency distributions for each survey item to determine consensus or discrepancy in opinion among participants. Open-ended responses were analyzed for major themes.

The audio-recorded focus group and interview responses were transcribed verbatim. Following Timpe-Laughlin's (2015) analytical approach, two of the authors developed an initial coding scheme by reviewing the word-level transcripts for emergent themes (general comments about the tasks, user experience/engagement with the tasks, and use of the tasks in instruction) and identifying subcategories in each theme (see Appendix II for the coding scheme). After the coding scheme was agreed upon, one of the authors who developed the coding scheme and a third researcher independently coded two-thirds of the transcripts, applying a code anytime a given aspect was mentioned by an interviewee. Intercoder agreement between the two coders across all codes was $87 \%$. Disagreements were resolved via a subsequent consensus coding.

To identify and examine patterns and thematic trends in the data, frequency counts were tallied of responses that received different codes. A small number of biased responses resulting from leading questions or prompts made by the focus group/interview facilitator were excluded from the analysis. Representative answers were extracted as a way of capturing and documenting response patterns in the words of the teachers.

\section{Results}

Findings are reported along the categories and themes that emerged from the survey and focus group/interview 
response data, including teachers' general perceptions of the dialogue-based interactions with a computer, their opinions about each of the different SDS-based activities, suggestions for potential improvements of the tasks, and their ideas for implementing the activities in their ESL instruction.

\section{General perceptions of the dialogue-based interactions with a computer}

Overall, participants $(N=16)$ appeared to like the SDS-based speaking activities, commenting positively about the interactive nature of the tasks, which they regarded as fun and engaging for their ESL learners. In their survey responses, five teachers provided rather general positive comments (e.g. 'Overall, I like them a lot. I find them fun and engaging. I think students would really like them'. [ID03]), while 11 instructors offered more specific rationales for their viewpoints. For example, ID07 noted that she 'like[d] the idea [...] that learners could potentially practice their speaking in various contexts in a low-stakes situation'. Along similar lines, ID09 argued that she could 'see them [i.e. the SDS tasks] being a fun way to engage and make low-level learners excited about speaking English, helping to boost their confidence'. Moreover, five teachers highlighted the tasks' resemblance to real-life interactions as particularly useful for ESL instruction because the speaking activities would allow learners at various levels of proficiency to engage in 'practical real life interactions' (ID12). This general stance was confirmed by five of the seven focus group participants who highlighted the 'bite sized' (ID05) format of these relatively short and specific tasks as fun, motivating, and engaging.

\section{Task-specific perceptions of the four SDS-based speaking activities}

In addition to providing general perceptions of the dialogue-based interactions with a computer, teachers were asked to give their opinions about each of the four speaking tasks by indicating their general perceptions and providing a more detailed explanation for their response relative to each task. As shown in Figure 5 the Request Boss task seemed to be the most popular speaking activity, followed by the Coffee Shop task, the Billing Dispute, and the Guessing Game. Thus, overall, perceptions appeared to be quite positive. However, certain aspects emerged that provide more nuanced insights into uncertain or negative responses. 


\section{Figure 5. Teachers' perceptions of the four SDS-based conversation tasks.}

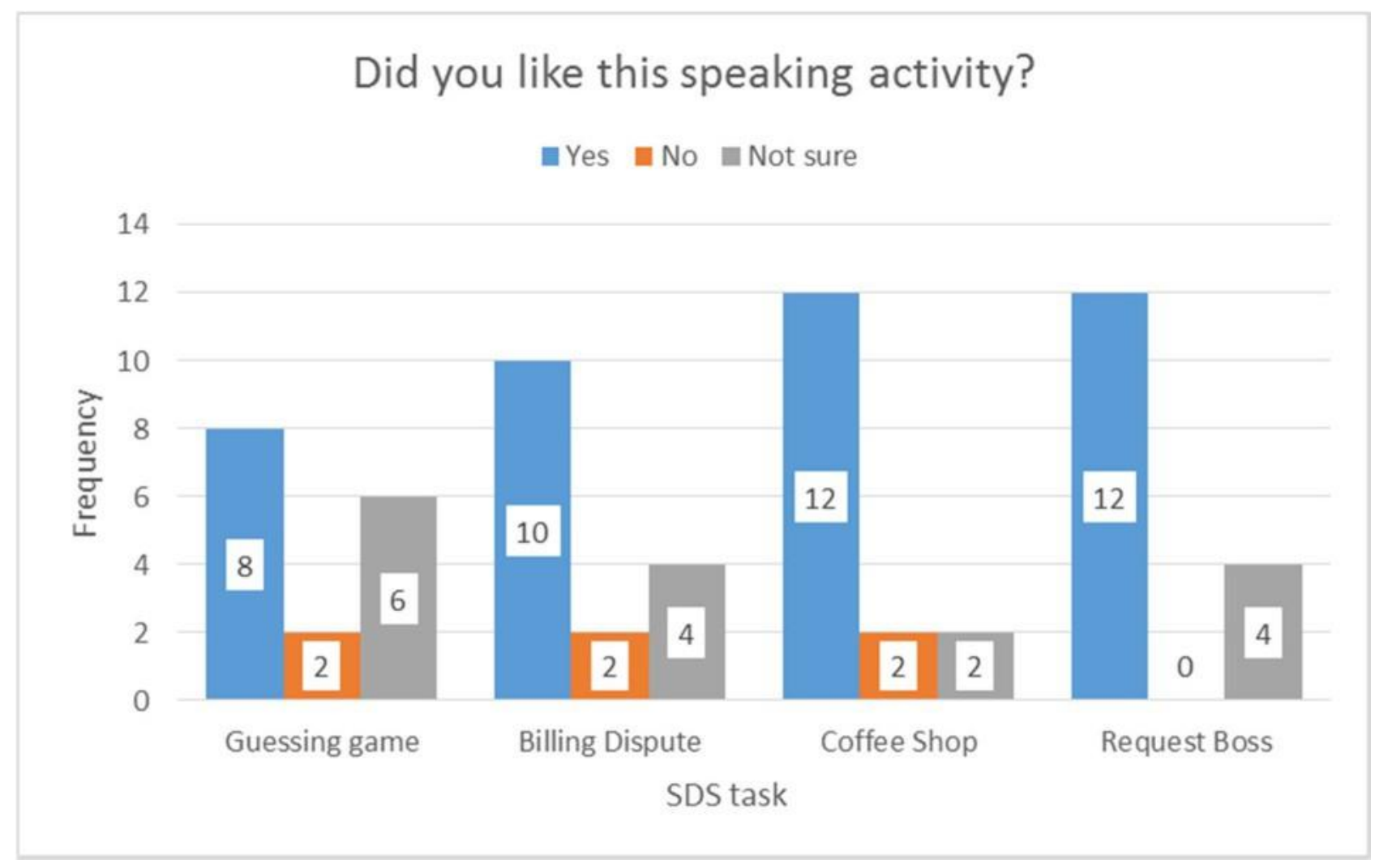

With regard to the Guessing Game, eight teachers indicated that they liked the activity, highlighting, in particular, the gamified language practice as a useful feature. For example, ID06 noted that she 'really like[d] this activity because I think the premise is great. Everyone loves a guessing game'. In particular, teachers commented positively on the opportunity for lower-level learners to practice yes-no questions. (ID06). Focusing more on the grammatical target structure, ID05 commented that ' [i]t was simple and would be easy to understand for my lower-level students. I like that it prompted me to ask $\mathrm{Y} / \mathrm{N}$ questions related to appearances, which can be [sic.] take a variety of forms and be challenging for beginners (i.e. do you have.../are you.../are you wearing)'. Teachers who indicated 'Not sure' $(n=2)$ primarily emphasized some concerns about the authenticity of the task, arguing that ' $[\mathrm{i}] \mathrm{t}$ 's not an authentic speaking activity that would be enacted in the real world, but it is good for practicing grammar' (ID11). Finally, the six uncertain evaluations all seemed to be related to the technical functionality of the ASR which did not seem to have worked well for some participants as indicated in the following remarks: 'The system did not understand me at first' (ID16) and 'I really love the idea of this task, but it didn't work well for me'.(ID14).

For the Billing Dispute, teachers $(n=10)$ who gave a positive task evaluation mainly commented on the authenticity of the scenario and the responses included in the task. ID02, for instance, stated that she 'like[d] it because it is an authentic task (students encounter problems with their mobile phone providers frequently and they are often overcharged)'. Focusing on the language embedded in the dialogue, ID08 highlighted that ' $[t]$ he language was authentic (it sounded like language that a real customer service representative would use). The responses also seemed like plausible reactions to my comments'. The four teachers who indicated that they were 'not sure' if they liked the activity seemed to have experienced technical challenges, which appeared to have impacted their general perception of the task. For example, ID06 argued that ' [a]t one point, I tried to explain why I was calling, and the woman interrupted me, which felt kind of frustrating'. Interestingly, the two teachers who reported that they did not like the task mainly seemed to highlight that they disliked the situation of having to dispute a bill(e.g. 'It is as frustrating as 
this activity is in real life! However, it is useful for life'. [ID15]). Nevertheless, they both commented that the task was quite authentic insofar as they had to engage in a similar task in real life. Overall, most instructors seemed to see value in this activity as it would provide their learners with the opportunity to practice a potentially challenging real-life encounter in a rather safe context.

As for the Billing Dispute, authenticity seemed to have been the teachers' main criterion for evaluating the Coffee Shop task. Teachers $(n=12)$ who liked the activity all commented on the authenticity of the task with regard to both scenario and the automated agent's language. For instance, ID06 emphasized that she 'like[d] that it's a really common kind of encounter to have. The questions were really typical, and the speaker sounded fairly natural'. The only critical point raised by teachers who indicated that they liked the activity concerned the image of the menu provided in the task. ID08, for example, highlighted that '[i]t was reasonably authentic, which I liked. However, the menu was limited, which made it seem less authentic'. Points of criticism made by teachers who indicated that they were either 'not sure' if they liked the activity $(n=2)$ or reported that they did not like it $(n=2)$ included either lack of task complexity (e.g. 'It was too basic'. [ID10]) or the simplistic image of the menu - a point that they highlighted as a potential task improvement (see below).

With regard to the Request Boss task, the four participants who commented critically (i.e. 'not sure') all referenced limited task complexity as the main reason for their evaluation, arguing that it 'seemed a little too easy or simple' (ID06), while the majority of the teachers $(n=12)$ who indicated that they liked the task emphasized two aspects that seemed to have contributed to their positive evaluations: (a) the perceived authenticity and feel of the open-ended conversation and (b) the functionality of the technology. With regard to authenticity, 10 teachers highlighted that the scenario and the responses provided by the computer were largely in line with a real-life interaction. For instance, ID03 commented that the Request Boss task felt 'realistic and the task involves two different requests [learners] need to form'. In particular, teachers seemed to value that the task gave 'the chance to use longer utterances than the other tasks [given that] it was a bit more open-ended' (ID05). Additionally, the image and voice of the putative interlocutor seemed to have contributed to their positive perception of it resembling a real-life interaction. As ID11 noted, she 'liked that it felt authentic and practical. The picture of Lisa make [sic.] me feel like I was actually talking with a real person'. Along similar lines, ID01 pointed out that she 'liked the tone of Lisa's voice and her manner. I liked how easily she was able to understand me'. While highlighting authenticity as the main driver, ID01's comment also touched upon a second critical feature: the functionality of the technology, a point that was summed up by ID16, who remarked that this task 'worked the best of all of them'.

\section{Suggestionsfor potentialtaskimprovements}

In the surveys, the ESL teachers were asked whether they had any suggestions for improving the different speaking tasks. With regard to the Guessing Game task, three teachers commented on increasing the level of complexity. In particular, they recommended including additional images of characters as well as additional versions of the game with other categories (e.g. animals). Moreover, seven teachers noted some technical issues when engaging with the task. For example, ID09 reported the following: '[T]he system told me I hadn't asked a yes/no question when I had. That was a bit annoying'. These ASR issues in the context of this task were confirmed in the focus group by three participants, who had also experienced these issues.

With respect to the Billing Dispute, 11 teachers commented on potentialimprovements relative to authenticity $(n=$ $1)$, scaffolding $(n=3)$, and functionality $(n=7)$. In terms of authenticity, one teacher commented that 'the customer service rep had a VERY clear accent. I always seem to get someone whose accent is different than my PNW [Pacific North Western] English sound. A SLIGHT accent might make this more realistic while keeping focus on the speaking interaction without being too much about the accent' (ID12). Three teachers pointed out the need to provide 
scaffolding such as 'some pre- and posttask activities' (ID07) or ' a set of phrases [for beginning-level students] to use' (ID02). Finally, with regard to functionality-related aspects, teachers suggested minor changes such as making 'the call button larger' (ID05), providing students with 'longer time to speak' (ID06), or improving the ASR because she 'had to repeat the account number a few times before the woman understood' (ID06).

In relation to the Coffee Shop task, 10 instructors provided ideas for further advancing the speaking activity. In particular, they advocated increasing the authenticity by revising the menu featured on the computer screen. For instance, ID11 argued that it might be beneficial to ' make the menu look more authentic by adding sizes and prices. Also perhaps include information about milk choices or toasting choices or hot/choices. Plus, I've never heard of toasting a croissant, a bagel, yes, but not a croissant, so that's not authentic for me, neither is a cold cappuccino... those are always justhot for me'. Moreover, they argued to includea picture of a worker in a coffee shop inorder to contextualize the tasks. In addition to authenticity and contextualization, teachers seemed particularly interested in testing the limits of the system. For example, ID06 recalled that' the only thing that didn't work so well was when I asked for the cream on the side. The computer guy wasn't able to process this and respond appropriately, and we had to cycle back through a couple of the questions. But, I guess this isn't really set up for spontaneity'. Overall, teachers seemed to aim for more interaction, highlighting that they would love to see more opportunities for unexpected dialogue.

Finally, with regard to the Request Boss task, nine instructors provided ideas, primarily aimed at increasing interaction and negotiation of meaning. For example, ID06 argued to 'maybe [include] more negotiation somehow? She could ask what the meeting is about or there could be more restrictions for possible meeting time so that there's more back and forth when arranging the time'. Along similar lines, ID07 noted that ' $[1]$ earners might benefit from some twist like Lisa changing her mind or after agreeing to one time, realizing that it actually conflicts with something else'. In the focus group, ID01 suggested to include a calendar featured on the screen in order to visually support the negotiation for learners. Thus, they proposed negotiation as a way to increase the length and interactivenature of the Request Boss task in order to provide learners with more opportunity to engage in potentially challenging aspects of conversations, while increasing task complexity.

\section{Potential implementation into ESL instruction}

Given that greater detail with regard to instructional use was provided in the (group) interviews, this section reports only the data from the interviews. Allteachers who participated in the interviews $(n=7)$ were willing to use theSDS tasks in their ESL classes. In particular, they identified two ways of implementation:(a) using tasks for supplementary speaking practice outside of the classroom and (b) utilizing the tasks for assessment purposes. Additionally, teachers considered the benefits and limitations of implementing the SDS activities in their ESL instruction.

All instructors ( $n=7)$ indicated that they would most likely use the SDS activities: 'as homework assignment[s]' (ID02) or 'extension activities outside of the classroom' (ID07) in order to minimize challenges such as noise issues, potential technological challenges, and classroom management issues. ID03, for instance, recalled an experience she had when she tried to administer an oral task to a whole class in the local speech lab, describing it as follows: 'I remembered when I tried to do recordings together and it'sjust like this loud, crazy chaotic scene. So, Idon't think that it would necessarily work well to have them do them in class.' Hence, the idea of using the tasks outside of the classroom seemed most feasible and beneficial.

However, five teachers also commented how they would connect the extension activities with in-class instruction, highlighting particular pretask and posttask activities. With regard to pretask activities, teachers indicated that they would address specific task-related aspects such as grammatical structures and cultural phenomena in class before 
assigning the speaking activities as homework. For example, ID05 argued that ' $[$ ] $]$ irst, [they] would practice the task in class and probably learn some target phrases that could be used in a specific task [i.e. how to order at a coffee shop, how to politely ask your boss for something]. Then, students could be assigned the tasks for homework'. Hence, preparing learners for the activities and scaffolding their interaction were considered key factors.

In a similar vein, ideas for post-task activities were provided, including awareness raising and expansion activities. With regard to awareness raising activities, ID03 noted that 'in class [...] you could show like three examples [of performances on a task], and say, okay, let' stalk about which one was the most successful'. ID01 expanded on the idea of using the Request Boss task as an example. She highlighted that she would have her learners focus on 'how the request was made. And how polite the request [was]... it would be interesting to debrief with your classmate on, 'well, I said, would you or wouldn't' and another could say 'I just said want' or, you know, and you could discuss those'. In terms of expansion activities, teachers also noted that they would have students create their own scripts and use role-plays to build on the speaking tasks, thus having 'them talking to each other, trying to mimic, mimic [sic.] or approximate the conversation with each other in the class' (ID05). Finally, teachers highlighted the potential for using scripts or videos of students' performances to have learners engage in self- or peer-assessment.

In addition to practice-oriented homework assignments, some teachers $(n=6)$ highlighted the tasks' potential for assessment purposes, emphasizing that they 'would use them as a speaking diagnostic or speaking evaluation' (ID15). Pointing toward time constraints in class, ID07 argued the following:

Speaking is hard to assess during class time, right? So, um, if I if I could send themhome to do a task like this [i.e. the Request Boss task], I could assess their pragmatics and pronunciation, I would havea video to score, uh, outside of class time. [... ] you could build a realy simple rubric too likeifyou succeeded in your communicationyouget 10 points, etc. So, I see it as a possibly attractiveassessment tool.

In the context of using the SDS-based tasks for assessment purposes, teachers regarded it as crucial to have access to students' performances in the form of videos and scripts. Elucidating the diagnostic aspect in reference to the Guessing Game task, ID03 argued that 'if somehow the videos came back to the instructor [...] And then you can watch them and see, oh, okay, we need to practice those yes/no questions more'. With regard to scoring responses, it appeared that teachers would rather provide the scores themselves, stating that 'maybe even the computer could give a kind of a score. I mean, I could kind of take it or leave it' (ID01). They seemed to view the scoring of responses not as a necessary, but appreciated this form of feedback to both themselves and their learners.

\section{Discussion}

In the following, we will discuss the findings relative to the two research questions.

\section{What do teachers think about the SDS-based tasks?}

In general, teachers seemed to have positive perceptions of the speaking activities. They regarded them as a motivating, fun, and safe environment for L2 speaking practice, thus echoing many of McGrath (2002) and Mishan and Timmis' (2015) main categories for teachers' evaluation of materials: how likely they are to motivate learners as well as the tasks' authenticity, clarity, and practicality. In particular, they seemed to regard authenticity as a critical feature insofar as tasks should resemble real-life activities and language use situations. Moreover, the teachers appeared to value activities that engaged learners in extended dialogues in which students needed to negotiate a particular problem across multiple turns in the conversation. While generally positive, their perceptions appeared to be mediated by the system's functionality (e.g. comments relative to the Guessing Game). Although a thorough ASR analysis is beyond the scope of this paper, it seemed to be the case that when tasks worked smoothly they tended to 
be perceived more positively than interactions in which teachers experienced communication breakdowns due to ASR (or speech processing) failures. Interestingly though, perceptions about technological functionality seemed to vary given that another instructor commented on the smoothness of the billing error task as creating a somewhat inauthentic experience. She argued that 'when [she] was listening [she] just felt like it's never that smooth with all the automated systems [i.e. automated customer service menus]' (ID02). Hence, this balance between a smooth technological experience and authentic, real-life interaction may need to be investigated systematically in future studies as this finding seems to imply that therein lies a potentially important difference for people's perceptions of authenticity.

\section{How would teachers use the tasks in the context of their English instruction?}

Overall, teachers identified two main ways of utilizing the SDS-based conversation tasks: (a) as supplementary practice materials outside of the classroom and $(b)$ as potential diagnostics for formative assessments. Teachers generally felt that such SDS-based tasks could be useful when practiced by learners individually outside of class. In particular, some teachers expressed their concern about using technology in the classroom - a finding that is in line with results presented by van Doremalen et al. (2016). The teachers highlighted the usefulness of supplementary speaking materials that could be used as an extension to what was being addressed in the classroom. In other words, they would ask students to engage with the tasks as homework, but would address the central grammar or culture points of an SDS-based task through pre- and posttask activities conducted in face-to-face classroom sessions. In order for these SDS tasks to be successfully used as supplementary speaking materials, tasks would need to be technologically robust and include basic feedback for the learner.

Moreover, many teachers believed that, due to time constraints, speaking skills could be only minimally assessed during classroom instruction. They focused on the potential of these tasks for formative and diagnostic assessment purposes. Teachers strongly expressed their wish to access transcripts or video-recordings of students' performances in order to use them either as additional information for diagnostic purposes or to conduct awareness raising activities in the classroom. In addition to providing access to students' responses, supplying teachers with a holistic assessment of the students' performance or a simple rubric for evaluation may increase usability. Hence, teachers' comments made it clear that such 'supplementary materials' have a somewhat strong impact on what is happening in the ESL classroom insofar as they would inform teachers about students' needs and influence the implementation of classroom activities.

In sum, future revisions as well as development efforts should take into account a number of aspects when creating new or refining these SDS-tasks. First, based on this group of teachers, task designers may need to ensure that the dialogues as well as accompanying materials, such as pictures, reflect real-life experiences as closely as possible. Second, they may want to extend the dialogues by creating more complex layers of interaction for more advanced learners, while eliminating as many technological issues as possible. Finally, they may need to consider creating a system for teachers to view students' videos for the purpose of assessment.

\section{Concluding remarks}

Following Mishan and Timmis' (2015) call for teacher input when developing instructional technology, our study provides first insights into ESL teachers' views and opinions of conversation-based SDS tasks. Earlier research studies conducted at the intersection of teachers' perceptions and SDS-based speaking activities mainly focus on usability and technological functionality (e.g. ASR error rates). However, no studies have examined teacher perceptions of SDS-based tasks that are highly goal-oriented (e.g. taking an erroneous charge off your phone bill), involve extended turn-taking, and do not provide error correction. Moreover, our study explored how teachers view 
the benefits and limitations of such technology for L2 instruction and, more specifically, how they would implement SDS-based speaking tasks in their specific teaching contexts, thus adding a pedagogical perspective.

In many contexts, teachers are the ones who make instructional decisions (i.e. not textbook authors or administrators). Our analysis of a variety of, sometimes conflicting, teachers' comments indicates that teachers indeed possess individual belief systems influenced by their prior knowledge, experiences, and worldviews (e.g. Borg, 2003, 2006). Notwithstanding some differences and similarities prevailed in teachers' perceptions of these SDS-based conversation tasks. Teachers' comments indicate that their putative criteria for effective SDS tasks are high authenticity, relevance to students; adequate complexity to trigger extended negotiation, general lack of technological issues, and ability to motivate and engage. These criteria align with the SLA theories/constructs that are most influential in current ESL/EFL teaching: Interaction Approach (negotiation), Task-Based Language Teaching (authenticity, tasks relevant to students), and the significant role of motivation and engagement in achieving language learning outcomes. Recurring themes in teachers' perceptions also point to the areas that SDS-based task designers should keep in mind when creating tasks.

With regards to limitations, it needs to be emphasized that we only examined teacher perceptions. Teacher cognition research has shown quite consistently that what teachers say they do may not necessarily be the same as what they actually do in the classroom (see e.g. Borg \& Alshumaimeri, 2019). Therefore, future research may want to go a step further and investigate, for example, by means of classroom observations with triangulating student interviews, how teachers implement SDS tasks in their actual instruction. Finally, we note that our results come from a small sample of teachers from a single instructional program, so the extent to which our findings generalize to other contexts is unclear. Additional studies of teachers' perceptions in varied contexts will help to provide a more comprehensive picture of teachers' attitudes toward SDS-based tasks and their potential instructional use. In particular, involving teachers in the preuse stage and then documenting the actual implementation by means of observations and interviews - similar to an impact study - would provide valuable insights into the feasibility of implementation as well as their efficacy for ESL instruction. Thus, we reiterate Mishan and Timmis' (2015) call to involve teachers more in the design of tasks and learning materials.

\section{References}

Alnajjar, M., \& Brick, B. (2019). Utilizing computer-assisted vocabulary learning tools in English language teaching: Examining in-service teachers' perceptions of the usability of digital flashcards. In M. Khosrow-Pour (Ed.), Computer-assisted language learning: Concepts, methodologies, tools, and applications (pp. 1038-1058). Hershey, PA: IGI Global.

Anderson, J. N., Davidson, N., Morton, H., \& Jack, M. A. (2008). Language learning with interactive virtual agent scenarios and speech recognition: Lessons learned. Computer Animation and Virtual Worlds, 19(5), 605-619. doi:10.1002/cav.265 $\square$

Arnold, N., \& Ducate, L. (2015). Contextualized views of practices and competencies in CALL teacher education research. Language Learning \& Technology, 19(1), 1-9. Retrieved from http://lt.msu.edu/issues/february2015/commentary.pdf $\square$

Ayedoun, E., Hayashi, Y., \& Seta, K. (2015). A conversational agent to encourage willingness to communicate in the context of English as a foreign language. In Proceedings of the Knowledge-Based and Intelligent Information \& Engineering Systems 19th Annual Conference (KES-2015) (Vol. 60, pp. 1433-1442). Singapore: Procedia. doi:10.1016/j.procs.2015.08.219 [10.1016/j.procs.2015.08.219] $\square$ 
Beatty, B., \& Ulasewicz, C. (2006). Faculty perspectives on moving from Blackboard to the Moodle learning management system. TechTrends, 50(4), 36-45. doi:10.1007/s11528-006-0036-y $\square$

Bernstein, J., Najmi, A., \& Ehsani, F. (1999). Subarashii: Encounters in Japanese spoken language education. CALICO Journal, 16(3), 361-384.

Bibauw, S., François, T., \& Desmet, P. (2015). Dialog-based CALL: An overview of existing research. In F. Helm, L. Bradley, M. Guarda, \&S. Thouesny (Eds.), Critical CALL-Proceedings of the 2015 EUROCALL Conference (pp. 57-64). Researchpublishing.net. doi:10.14705/rpnet.2015.000310

Bibauw, S., François, T., \& Desmet, P. (2019). Discussing with a computer to practice a foreign language: From a conceptual framework to a research agenda for dialogue-based CALL. Computer Assisted Language Learning, 32(8), 827-877. doi:10.1080/09588221.2018.1535508

Borg, S. (2003). Teacher cognition in language teaching: A review of research on what language teachers think, know, believe, and do. Language Teaching, 36(2), 81-109. doi:10.1017/S0261444803001903

Borg, S. (2006). Teacher cognition and language education: Research and practice. New York, NY: Continuum.

Borg, S., \& Alshumaimeri, Y. (2019). Language learner autonomy in a tertiary context: Teachers' beliefs and practice. Language Teaching Research, 23(1), 9-38. doi:10.1177/1362168817725759

Bunting, J. D. (2013). An investigation of language teachers' explorations of the use of corpus tools in the English for Academic Purposes (EAP) class (Doctoral dissertation). Scholarworks @ Georgia State University. Retrieved from https://scholarworks.gsu.edu/alesl_diss/26

Bueno Alastuey, M. C. (2011). Perceived benefits and drawbacks of synchronous voice-based computer-mediated communication in the foreign language classroom. Computer Assisted Language Learning, 24(5), 419-432. doi:10.1080/09588221.2011.574639

Chao, C.-C. (2015). Rethinking transfer: Learning from CALL teacher education as consequential transition. Language Learning \& Technology, 19(1), 102-118.

Chen, H. N. (2011). Developing and evaluating an oral skills training site supported by automatic speech recognition technology. ReCALL Journal, 23(1), 59-78. doi:10.1017/S0958344010000285

Cucchiarini, C., \&Strik, H. (2019). Second language learners' spoken discourse: Practice and corrective feedback through automatic speech recognition. In M. Khosrow-Pour (Ed.), Computer-assisted languagelearning: Concepts, methodologies, tools, and applications (pp. 787-810. Hershey, PA: IGI Global.

DeKeyser, R. (Ed.). (2007). Practicing in a second language: Perspectives from applied linguistics and cognitive psychology. Cambridge: Cambridge University Press.

DeKeyser, R. (2010). Practice for second language learning: Don't throw out the baby with the bathwater. International Journal of English Studies, 10(1), 155-165. doi:10.6018/ijes/2010/1/114021

Dippold, D. (2009). Peer feedback through blogs: Student and teacher perceptions in an advanced German class. ReCALL, 21(1), 18-36. doi:10.1017/S095834400900010X 
Egbert, J., Huff, L., McNeil, L., Preuss, C., \&Sellen, J. (2009). Pedagogy, process, and classroom context: Integrating teacher voice and experience into research on technology-enhanced language learning. The Modern Language Journal, 93, 754-768. doi:10.1111/j.1540-4781.2009.00971.x

Ellis, N. C., \& Bogart,P. (2007). Speech and language technology ineducation: The perspective from SLA research and practice. In Proceedings of the SlaTE Workshop on Speech and Language Technology in Education ISCA Tutorial and Research Workshop (pp.1-7). Retrieved from https://www.iscaspeech.org/archive_open/slate_2007/sle7_001.html

Eskenazi, M. (2009). An overview of spoken language technology for education. Speech Communication, 51(10), 832-844. doi:10.1016/j.specom.2009.04.005

Evanini, K., Timpe-Laughlin, V., Tsuprun, E., Blood, I., Lee, J., Bruno, J., Suendermann-Oeft, D. (2018). Game-based spoken dialog language learning applications for young students. Proceedings from the 2018 Interspeech Conference (pp. 548-549). Retrieved from https://www.isca-speech.org/archive/Interspeech_2018/pdfs/3045.pdf

Godwin-Jones, R. (2009). Emerging technologies speech tools and technologies. Language Learning \& Technology, $13(3), 4-11$.

Golonka, E.M., Bowles, A.R., Frank, V.M., Richardson, D.L., \&Freynik, S. (2014). Technologies for foreign language learning: A review of technology types and their effectiveness. Computer Assisted Language Learning, 27(1), 70-105. doi:10.1080/09588221.2012.700315

Hjalmarsson, A., Wik, P., \& Brusk, J. (2007). Dealing with DEAL: A dialogue system for conversation training. In Proceedings of SIGDIAL (pp. 132-135).

Hubbard,P.(2008). CALL and the future of languageteacher education. CALICO Journal, 25(2), 175-188.

Johnson, W. L., \& Valente, A. (2009). Tactical language and culture training systems: Using AI to teach foreign languages and cultures. AI Magazine, 30(2), 72. doi:10.1609/aimag.v30i2.2240

Lee, S., Noh, H., Lee, J., Lee, K., \& Lee, G. G. (2012). Foreign language tutoring in oral conversations using spoken dialog systems. IEICE Transactions on Information and Systems, 95(5), 1216-1228. doi:10.1587/transinf.E95.D.1216

Long, M. H. (2015). Second language acquisition and task-based language teaching. Malden, MA:WileyBlackwell.

Madsen,K.S., \& Bowen,J. D.(1978).Adaptation in languageteaching. Boston, MA:Newbury House.

McGrath, I. (2002). Material evaluation and design for language teaching. Edinburgh: Edinburgh University Press.

Mishan, F., \& Timmis, I. (2015). Materials developmentfor TESOL. Edinburgh:Edinburgh University Press.

Morton, H., Gunson, N., \& Jack, M.A. (2012). Interactive language learning through speech enabled virtual scenarios. Advances in Human-Computer Interaction, 2012, 1-14. doi:10.1155/2012/389523

Pica, T. (2013). From input, output and comprehension to negotiation, evidence, and attention: An overview of theory and research on learnerinteraction and SLA.InM. delPilar García Mayo, M. Juncal Gutiérrez Mangado, \& 
M. Martmez-Adrian (Eds.), Contemporary approaches to second language acquisition (pp.49-70). Amsterdam: John Benjamins.

Plonsky, L., \& Gass, S. M. (2011). Quantitative research methods, study quality, and outcomes: The case of interaction research. Language Learning, 61(2), 325-366. doi:10.1111/j.1467-9922.2011.00640.x

Ramanarayanan, V., Suendermann-Oeft, D., Lange, P., Mundkowsky, R., Ivanov, A. V., Yu, Z., Evanini, K. (2017). Assembling the jigsaw: How multiple open standards are synergistically combined in the HALEF multimodal dialog system. InD. A. Dahl(Ed.), Multimodal interaction with W3C standards: Towards natural user interfaces to everything, (pp. 295-310). Switzerland: Springer.

Roush, C., \& Song, L. (2013). The impact of using Clickers technology on classroom instruction: Students' and teachers' perspectives. Canadian Journal of Action Research, 14(1), 21-37.

Saraceni, C. (2003). Adapting courses: A critical view. In B. Tomlinson (Ed.), Developing materials for language teaching (pp. 72-85). London: Continuum.

Suendermann-Oeft, D., Ramanarayanan, V., Teckenbrock, M., Neutatz, F., \&Schmidt, D. (2015). HALEF: An open-source standard-compliant telephony-based modular spoken dialog system - A review and an outlook. In G. Lee, H. Kim, M. Jeong, \& J.-H. Kim (Eds.), Natural language dialog systems and intelligent assistants. Switzerland: Springer.

Surface, E.A., Dierdorff, E.C., \&Watson, A. M. (2007). Special operations language training software measurement of effectiveness study: Tactical Iraqi study final report (Technical Report No. 2007010602). Special Operations Forces Language Office of the United States Special Operations Command. Retrieved from https://rdl.train.army.mil/catalog/view/100.ATSC/56F12B52-936B-4B85-A11D-44D3F590E2DF1274550929321/BCKStest/ussocom_tactical_iraqi_study_final_report_swa_20070501.pdf

Timpe-Laughlin, V.(2015). Evaluating a learning tool for young English learners: The case of the TOEFL® Primary ${ }^{T M}$ English Learning Center (Research Memorandum No. RM-15-04). Educational Testing Service.

Timpe-Laughlin, V., \& Evanini, K. (in press). Bridging the gap: Teaching L2 pragmatics to foster intercultural language learning. In AKS Conference Proceedings. Klassisch-Modern digital: Fremdsprachenlehre an Hochschulen zwischen Tradition und Moderne.

Timpe-Laughlin, V., Evanini, K., Green, A., Blood, I., Dombi, J., \& Ramanarayanan, V. (2017). Designing interactive, automated dialogues for L2 pragmatics learning. In V. Petukhova \& Y. Tian (Eds.), Proceedings of the 21st Workshop on the Semantics and Pragmatics of Dialogue (pp. 143-152). Retrieved from http://www.saardial.uni-saarland.de/wordpress/wp-content/uploads/SemDial2017SaarDial_proceedings.pdf

Tomlinson, B. (Ed.). (2003). Developing materials for language teaching. London: Continuum.

Tomlinson, B., \& Masuhara, H. (2004). Developing language course materials. Singapore:RELC Portfolio Series.

van Doremalen, J., Boves, L., Colpaert, J., Cucchiarini, C., \&Strik, H. (2016). Evaluating automatic speech recognition-based languagelearning systems: A case study. Computer Assisted Language Learning, 29(4), 833-851. 
van Praag, B., \& Sanchez, H.S. (2015). Mobile technology in second language classrooms: Insights into its uses, pedagogical implications, and teacher beliefs. ReCALL, 27(3), 288-303. doi:10.1017/S0958344015000075

Warschauer, M. (1998). Researching technology in TESOL: Determinist, instrumental, and critical approache.s TESOL Quarterly, 32(4), 757-761. doi:10.2307/3588010

Warschauer, M. (1999). Electronic literacies: Language, culture and power in online education. Mahwah, NJ: Lawrence Erlbaum.

Warschauer, M., \& Cook, J. (1999). Service learning and technology in TESOL. Prospect, 14(3), 32-39. 